\title{
Great arterial potential in radiofrequency ablation of ventricular arrhythmias
}

\author{
Zoran Bakotić, Ante Anić, Marin Bištirlić \\ Zadar General Hospital, Zadar, Croatia
}

Ablation success for coronary cusp ventricular arrhythmias is predicted by timing, not by a mere presence of great arterial potential.

Purpose: To investigate the predictive value of presence and timing of typical potentials registered during ablation for ventricular arrhythmias above coronary cusps.

Methods: Between May 2011 and December 2013, we performed radiofrequency (RF) ablation for ventricular arrhythmias above coronary cusps in 11 patients. In each case careful search for potentials that represent activation of myocardial extension into aortic root was done, the so called great arterial potential (GAP).

Results: GAP was registered in 9/10 patients (Figure 1). Timing range in respect to QRS onset was $50-116 \mathrm{~ms}$. In 3

Received: 30 $30^{\text {th }}$ Apr 2014

*Address for correspondence: Opća bolnica Zadar, Bože Peričića 5, HR-23000 Zadar, Croatia.

Phone: +398-98-1973-264

E-mail: zbakotic@gmail.com patients, the first ablation attempt at sites with GAP being less than $50 \mathrm{~ms}$ before QRS onset had no effect on ectopic activity. No lesion with GAP being $50 \mathrm{~ms}$ or more in front of QRS onset was without effect, exhibiting partial or complete suppression of arrhythmia.

Conclusions: By using careful mapping, GAP can be registered in most of the patients with coronary cusps ventricular arrhythmias. In our series it was registered in $90 \%$ of patients. In $3 / 8$ patients the ablation attempt at sites with GAP being less than $50 \mathrm{~ms}$ before QRS failed to show any effect. Conversely, all lesions at sites with GAP being $50 \mathrm{~ms}$ or more before QRS showed effect, mostly complete suppression of arrhythmia within seconds after RF delivery start. Thus, when ablating above coronary cusps, one should not only rely on mere presence of GAP yet map extensively till registering signal being $50 \mathrm{~ms}$ or more before QRS.

KEYWORDS: ventricular arrhythmias, radiofrequency ablation, coronary cusps, great arterial potential.

CITATION: Cardiol Croat. 2014; 9(5-6):207.

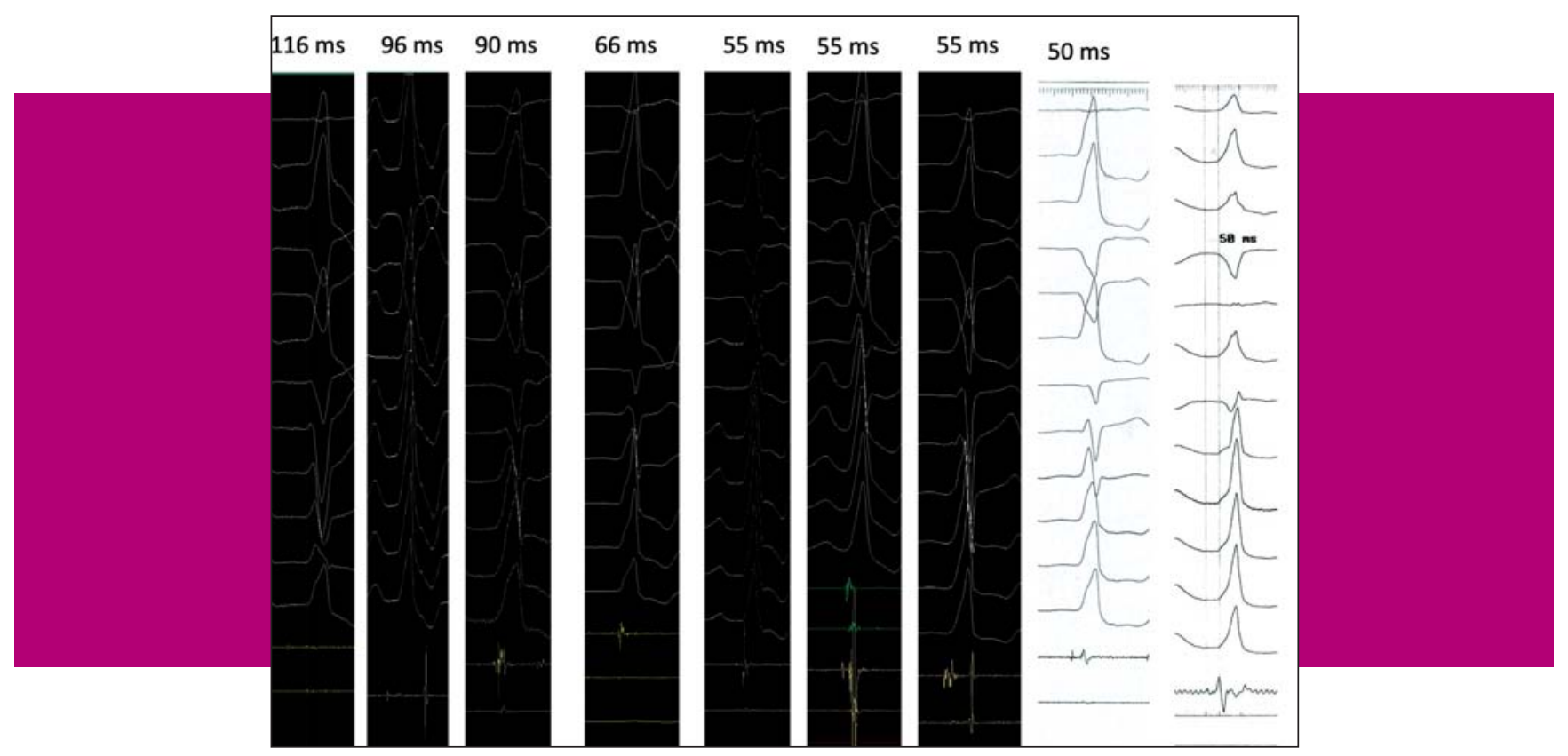

\section{Literature}

1. Hitoshi H, Yasuteru Y, Yoshito I, et al. Discrete prepotential as an indicator of successful ablation in patients with coronary cusp ventricular arrhythmia. Circ Arrhythm Electrophysiol. 2013;6:898-904 